\title{
Emotional Intelligence of College Level Students In Relation to Their Gender
}

\author{
Sanjay K. Patel ${ }^{1 *}$
}

\section{ABSTRACT}

The present investigation in to find out the Emotional Intelligence of college level Students in Relation to their gender boys and girls. The sample consisted of 120 college level students out of which 60 where boys and 60 where girls. For this purpose of investigation "Emotional Intelligence Inventory” by S.K. Mangal and Shubhra Mangal was used. The obtained data were analyzed through ' $t$ ' test to know the mean difference between college level students in relation to their gender. The result shows that there is significant difference in Emotional Intelligence of boys and girls. It means girls are high emotional intelligence than boys. One more significant difference between arts college students and commerce college students it means arts college students emotional intelligence high than commerce college students.

Keywords: Emotional Intelligence, Boys, Girls

Emotional intelligence focuses on the softer skills of building and maintains human relationships. This aspect of life assumes a lot of importance since a person is not detached from the human element, be it work place, the home front or the social circle, human interactions are inevitable and our success depends to a large extent on what we make of these interactions and relationships.

Bar-On's model of emotional intelligence relates to the potential for performance and success, rather than performance or success itself, and is considered process-oriented rather than outcome-oriented. It focuses on an array of emotional and social abilities, including the ability to be aware of , understand and express oneself, the ability to be aware of understand, the ability to deal with strong emotions, and ability to adapt to change and solving problems of a social or personal nature.

The term emotional intelligence was launched when people started to realize that a high Intelligence Quotient (IQ) is no guarantee against failure in everyday life. Whereas others with

${ }^{1}$ Ph.D Scholar, Hemchandracharya North Gujarat University,Gujarat, India

*Responding Author

Received: December 24, 2016; Revision Received: January 25, 2017; Accepted: February 2, 2017

(C) 2017 Patel S; licensee IJIP. This is an Open Access Research distributed under the terms of the Creative Commons Attribution License (www.creativecommons.org/licenses/by/2.0), which permits unrestricted use, distribution, and reproduction in any Medium, provided the original work is properly cited. 


\section{Emotional Intelligence of College Level Students In Relation To Their Gender}

an average IQ succeed. At best IQ contributes about $20 \%$ to the factors that determine life success, which leaves $80 \%$ to other forces. So if we want to succeed in life, we need to introduce our emotions very well.

Researchers investigated dimensions of emotional intelligence (EI) by measuring related concepts, such as social skills, interpersonal competence, psychological maturity and emotional awareness, long before the term 'Emotional Intelligence' came into use. The most distant roots of emotional intelligence can be traced to Charles Darwin's (1872) early work on the importance of emotional expression for survival and second adaptation. In the 1900s, even though traditional definitions of intelligence emphasized cognitive aspects such as memory and problem solving, several influential researchers in the intelligence field of study has begun to recognize the importance of no cognitive aspects. For instance, as early as 1920, E.L. Thorndike used the term social intelligence. Psychologist have been uncovering other intelligences for some time now, and grouping them mainly into three clusters: abstract intelligence (the ability to understand and manipulate with verbal and mathematics symbols), concrete 6 intelligence (the ability to understand and manipulate with objectives), and social intelligence (the ability to understand and relate to people). Thorndike (1920) defined social intelligence as "the ability to understand and manage men and women, boys and girls-to act wisely in human relations".

Bar-On (2005) explored the concept and calls it Emotional-Social intelligence. It is "a cross section of interrelated emotional and social competencies, skills and facilitators that determine how effectively we understand and express ourselves, understand other and relate with them, and cope with daily demands.”(p.4)

Goleman (1998) defines Emotional Intelligence as the "the capacity for recognizing our own feelings and those of others, for motivating ourselves and for managing emotions well in ourselves and in our relationships” (p.375).

Singh, S.K (2003) proposed three dimensions of Emotional Intelligence. He defines EI as "the ability of an individual to appropriately and successfully respond to a vast variety of emotional stimuli being elicited from the inner self and immediate environment. Emotional intelligence constitutes three psychological dimensions - emotional 22 competency, emotional maturity and emotional sensitivity - which motivate an individual to recognize truthfully, interpret honestly and handle tactfully the dynamics of human behaviour" (pp.38-39)

Srivsastava and Bharamanaikar in 2004 examined leadership effectiveness with a unique population of 291 Indian army officers. EI was measured using a self-report measure, the Work Profile Questionnaire Emotional Intelligence version (WPQei) and Leadership style was measured by the 5x-short version of the Multifactor Leadership Questionnaire (MLQ). Perceived success of the leaders was measured by a questionnaire developed by Pareek and Rao and job 


\section{Emotional Intelligence of College Level Students In Relation To Their Gender}

satisfaction was measured by the Job Satisfaction Survey developed by Spector. MLQ was completed by subordinates allowing subordinates to determine the extent that transformational and transactional leadership style was displayed in the leaders. The results significantly supported the connection between leader's EI and all of the components of the transformational leadership style. Higher EI scores were also found for the contingent reward component of transactional style. EI was not related to job satisfaction, but was related to perceived success. EI was not related to job satisfaction, but was related to perceived success. There was a strong relationship between transformational leadership behaviors and the leader's self-reports of being innovative, intuitive, self-aware, motivated, socially adept, empathic, and managing emotions. The army officers who rated themselves high on EI also perceived themselves to be more successful in their careers.

Koman and Wolff in 2008 conducted a study in military organizations. The objective of this study was to assess the relationship between individual emotional intelligence competencies, team level emotional intelligence, and team effectiveness. 70 team leaders and 73 managers (team leaders' supervisors) rated team leaders' emotional intelligence. A total of 349 aircrew and maintenance team members participated representing 81 aircrew and maintenance teams. To assess team leader emotional intelligence, the emotional competence inventory (ECI-2) was administered. Each team leader had 2-14 raters rate their behaviors, with an average of 4.34 ratings completed for every team leader, excluding the self-rating. Team level emotional intelligence was assessed using the Group Emotional Intelligence measure developed by Druskat and Wolff and later refined based on work by Hamme. Team member participants self rated their team's behavior according to each of the nine ECG norms measured by the instrument. The objective performance rating was calculated from the percentage of goals attained by each team on measures used in respective military organization. Subjective performance measures were gathered from upper level officers who had observed multiple teams within the command over time. This study showed that a team leader's emotional intelligence affects team level emotional competence and team performance through the development of ECGNs. Team leader EI levels were significantly related to performance

Wolff and Koman (2007) conducted a study in military organizations. The objective of this study was to assess the relationship between individual emotional intelligence competencies, team level emotional intelligence, and team effectiveness. 70 team leaders and 73 managers (team leaders' supervisors) rated team leaders' emotional intelligence. A total of 349 aircrew and maintenance team members participated representing 81 aircrew and maintenance teams. To assess team leader emotional intelligence, the emotional competence inventory (ECI-2) was administered. Each team leader had 2-14 raters rate their behaviors, with an average of 4.34 ratings completed for every team leader, excluding the self-rating. Team level emotional intelligence was assessed using the Group Emotional Intelligence measure developed by Druskat and Wolff and later refined based on work by Hamme. Team member participants self rated their 


\section{Emotional Intelligence of College Level Students In Relation To Their Gender}

team's behavior according to each of the nine ECG norms measured by the instrument. The objective performance rating was calculated from the percentage of goals attained by each team on measures used in respective military organization. Subjective performance measures were gathered from upper level officers who had observed multiple teams within the command over time. This study showed that a team leader's emotional intelligence affects team level emotional competence and team performance through the development of ECGNs. Team leader EI levels were significantly related to performance

Singh Chaudhary and Asthana (2008) on impact of gender on emotional intelligence of adolescents, among a sample of 400 adolescents (200 male and 200 female) from various schools and colleges. The results revealed that male and female adolescents exhibit some emotional intelligence, concluding that both male and female adolescents are caring, giving, supportive and enriching.

Lopes, Salovey and Straus (2003) had explored links between emotional intelligence and interpersonal relationships; in a sample of 103 college student and found that individuals scoring highly on the managing emotions subscale of the Mayer, Salovey and Caruso emotional Intelligence test (MSCEIT), were more likely to report positive relations with others, as well as perceived parental support and less likely to report negative interactions with close friends.

Boyatzis et al. (2013) concluded in a recent publication in 2013 that emotional and social intelligence competencies have been shown to predict effectiveness in leadership, management and professional jobs in many countries of the world. To be an effective leader, manager or professional, a person needs to understand and skillfully manage his emotions appropriately based on each person or situation and understand the emotional cues of others in order to effectively interact with others.

\section{Objective of the study}

The main objectives of the study were as under:

1. The purpose of the present study is the difference related to the Emotional Intelligence of college level students in relation to their gender.

\section{Hypothesis}

1. There is no significant difference between Emotional Intelligence of college level students in relation to their gender.

2. There is no significant difference between Emotional Intelligence of arts college students and commerce college students. 


\section{METHODOLOGY}

\section{Sample}

The present study was carried out on college level students of Ahmedabad city of the study are 120 college students out of which 60 were boys and 60 were girl's college students.

\section{Tools}

In the present investigation measure the Emotional Intelligence "Emotional Intelligence Inventory” S.K. Mangal and Shubhra Mangal was used. The Emotional inventory consists 100 items with yes or no response pattern. The reliability factor is Split Half 0.89 and testretest 0.92 \& validity for the inventory has been established by adopting two different approaches, namely factorial and criterion related approach.

\section{Procedure}

The boys and Girls, who were studying in college of different stream in Ahmedabad District, were randomly selected "Emotional Intelligence Inventory" S.K. Mangal and Shubhra Mangal was give \& data was collected. The obtain data form 120 boys and girls were analyzed with the help of mean, SD and't' test.

\section{RESULTS \& DISCUSSION}

The main objective of present study was to do study of Emotional Intelligence of The College students among boys and girls. In it statistical' method was used and their correlation was measured. Results discussions of present study are as under:

Table No: 1: Showing the Mean, SD and't' value of Emotional Intelligence of college students among boys and girls.

\begin{tabular}{|l|c|c|c|c|c|c|c|}
\hline Variable & No. & Mean & SD & Mean diff & SED & 't' & Sig \\
\hline Boys & 60 & 55.32 & 11.11 & 4.73 & 2.16 & 2.182 & 0.05 \\
\hline Girls & 60 & 60.05 & 12.60 & & & & \\
\hline
\end{tabular}

Significant at 0.05 levels.

The above result table No.1 we can see that ' $t$ ' test was used to know the level of Emotional Intelligence of college level students among boys and girls. Where boys mean was55.32 \& SD was 11.11 and girls mean was 60.05 \& SD was 12.60 and difference between their ' $t$ ' values was 2.182 it was no significance at 0.05 level. The result shows that there is significant mean difference emotional intelligence of college level student in boys and girls. Thus the null hypothesis, 1 which states "there is no significant difference in the Emotional intelligence level of college level students with respects to their Emotional Intelligence" significant difference between boys and girls. it means girls are high emotional intelligence than boys. Because girls are understanding the emotions of self and Self aware and have a high degree of self confidence 


\section{Emotional Intelligence of College Level Students In Relation To Their Gender}

and knowledge of their abilities. There are provides better education, good facilities and so many things.

Table No. 2: Showing the Mean, SD and 't' value of Emotional Intelligence of college level students among arts and commerce college students.

\begin{tabular}{|l|c|c|c|c|c|c|c|}
\hline Variable & No. & Mean & SD & Mean diff & SED & 't' & Sig \\
\hline Arts & 60 & 59.93 & 13.80 & 4.31 & 2.15 & 1.999 & 0.05 \\
\hline Commerce & 60 & 55.62 & 9.45 & & & & \\
\hline
\end{tabular}

Significant at 0.05 levels.

The above result table No. 2 we can see that ' $t$ ' test was used to know the level of Emotional intelligence college level students among arts college students and commerce college students. Where arts college students mean was 59.93 \& SD was 13.80 and commerce college students mean was 55.62 \& SD was 9.45 and difference between their ' $t$ ' values was 1.999 it was significance at 0.05 level. The result shows that there is significant mean difference emotional intelligence of college level Student in arts college students and commerce college students. Thus the null hypothesis, 2 which states “ There is significant difference in the emotional intelligence level of college students with respects to their emotional intelligence " Here null hypothesis was rejected and result shows that the emotional intelligence is high level of arts college students than commerce college students because arts college students are better education and expectations of society and people around, In this study, emotional parents, are different in terms of children's sexuality. Intelligence had overlapping with self-respect and hidden culturally, meaningfully higher feelings, whereas abstaining from feelings expression in overall emotional intelligence, emotion understanding good than commerce college students.

\section{CONCLUSION}

We can conclude by data analysis as follows:

1. There is significant mean difference in emotional Intelligence of college level students in relation to their gender. it means girls are higher emotional intelligence than the boys.

2. There is significant mean difference in emotional intelligence of college level students in relation to their arts and commerce college students it means arts college students are higher emotional intelligence than the commerce college students.

\section{Acknowledgments}

The author appreciates all those who participated in the study and helped to facilitate the research process.

Conflict of Interests: The author declared no conflict of interests. 


\section{REFERENCES}

Bar-On, R. (2001). Emotional intelligence and self-actualization. In Joseph Ciarrochi,Joe Forgas, and John D. Mayer (Eds.), Emotional intelligence in everyday life: A scientific inquiry. New York: Psychology Press.

Bar-On, R., \& Fund, S. (2004). The impact of emotional and social intelligence on self-perceived physical health. Unpublished manuscript.

Bar-On, R., Handley, R., \& Fund, S. (2005). The impact of emotional and social intelligence on performance. In Vanessa Druskat, Fabio Sala, and Gerald Mount (Eds.), Linking emotional intelligence and performance at work: Current research evidence. Mahwah, NJ: Lawrence Erlbaum.

Bar-On,R(1997),Emotional intelligence Quotient inventory: A Measure of Emotional Intelligence, Toronto, ON Multi Health. Inc.

Boyatzis, R. E.,(2013) Competencies as a behavioral approach to emotional intelligence” Journal of Management Development, Vol. 28, No. 9, pp. 749-770, 2009.

Goleman, D. (1998). Working with emotional intelligence. New York: Bantam Books.

Goleman, D. 1998. Working with Emotional Intelligence. New York: Bantam Books.

Lopes, P. N., Salovey, P., \& Straus, R. (2003). Emotional intelligence, personality, and the perceived quality of social relationships. Personality and individual Differences, 35(3), 641-658.

Mangal, S. K. \& Mangal S. (2009). Manual for Mangal Emotional Intelligence Inventory. National Psychological Corporation, Agra.

Singh, M. C. (2008). OP and Asthana, M. Impact of locale and gender on emotional intelligence of adolescents. Psycho-Lingua ISSN, 0377-3132.

Singh, S.K., "Emotional intelligence and organizational leadership: a gender study in Indian context”, Int. J. of Indian Culture and Business Management, Vol.1, Nos1/2, pp. 48-63, 2007.

Srivsastava, B.L. \& Bharamanaikar, S.R., (2004) "Emotional intelligence and effective leadership behavior,. Psychological Studies, 49, pp. 107-113, 2004.

Wolf, S.B.(2007) Emotional and social competence inventory technical manuals”. Hay Group, Boston, MA, 2007.

How to cite this article: Patel S (2017), Emotional Intelligence of College Level Students In Relation To Their Gender, International Journal of Indian Psychology, Volume 4, Issue 2, No. 87, ISSN:2348-5396 (e), ISSN:2349-3429 (p), DIP:18.01.056/20170402, ISBN:978-1-36571287-6

(c) The International Journal of Indian Psychology, ISSN 2348-5396 (e)| ISSN: 2349-3429 (p) | 128 